\title{
Jaggery and Tea Workers Perceptions on the Use of ITNs in Prevention of Malaria in South Mugirango Sub- County, Kisii County, Kenya
}

\author{
Masta Ondara Omwono $^{1}$, Justus Oseno Osero ${ }^{2}$, Alloys Sigar Steven Orago ${ }^{3}$, Taratisio Ndwiga ${ }^{4}$ \\ ${ }^{1}$ Public Health, Moi University, Eldoret, Kenya \\ ${ }^{2}$ Department of Community Health, Kenyatta University, Nairobi, Kenya \\ ${ }^{3}$ Department of Pathology, School of Medicine, Kenyatta University, Nairobi, Kenya \\ ${ }^{4}$ Department of Environmental Health, School of Public Health, Moi University, Eldoret, Kenya
}

Email address:

omwono76@gmail.com (M. O. Omwono), oseroj@yahoo.com www.ku.ac.ke (J. O. Osero),

orago.alloysss@ku.ac.ke /www.ku.ac.ke (A. S. S. Orago), taratisiondwiga@yahoo.com (T. Ndwiga)

\section{To cite this article:}

Masta Ondara Omwono, Justus Oseno Osero, Alloys Sigar Steven Orago, Taratisio Ndwiga. Jaggery and Tea Workers Perceptions on the Use of ITNs in Prevention of Malaria in South Mugirango Sub- County, Kisii County, Kenya. World Journal of Public Health.

Vol. 3, No. 1, 2018, pp. 1-8. doi: 10.11648/j.wjph.20180301.11

Received: November 18, 2017; Accepted: December 15, 2017; Published: January 16, 2018

\begin{abstract}
Background; An estimated 51.6\% of adults by age distribution among the Jaggery and Tea workers aged 18-49 years are at risk of contracting malaria due to improper use of ITNs in South Mugirango Sub County. Kisii County, Kenya. This is due to their perception and the reasons for not sleeping under ITNs. Published data on ITNs use among the Jaggery and Tea workers in South Mugirango Sub County are limited. The purpose of this study is to establish the Jaggery and Tea workers perception on ITNs use. Methods; A descriptive cross sectional study was used, where South Mugirango was purposively selected. The study systematically and randomly selected and interviewed 209 Jaggery and Tea workers on ITNs use. Qualitative methods were used to investigate their perceptions on ITNs use. Data was also collected via structured questionnaire, focused group discussion and Key informant interviews to obtain views. Results; Overall 209 Jaggery and Tea workers were selected and interviewed; $116(56 \%)$ males and 93 (44\%) females, about 52\% perceived mosquitoes to cause malaria and $77.3 \%$ cited the main reasons of not using the ITNs as to cause suffocation, irritation and dreams. There was a positive relationship between gender and education on ITNs use $(\mathrm{P}<0.001$, $)$ respectively. There was also significant relationship between cost, accessibility and house structure and ITNs use $(\mathrm{P}<0.0010)$ while age and marital status were not statistically significant. Conclusion and recommendations; The $77.3 \%$ who perceived that ITNs causes suffocation, irritation and dreams is high number as malaria is on the rise among the study group. Therefore the study recommends; (a) Policy review on ITNs use among the Jaggery and Tea workers (b) Intensive health training on perception and beliefs on ITNs to improve its use with adoption of door to door awareness creation on the importance of ITNs use.
\end{abstract}

Keywords: Insecticide Treated Nets, Infection, Malaria, Risk

\section{Introduction}

Globally ITNs have been advocated as the most important strategy in combating malaria in high endemic areas of the world where by half of its population was at risk. Middle East, Asia, and Latin America recorded high incidence and prevalence among the travellers and immigrants with low immunity [1]. Over half of the world population was exposed to malaria and 240 million contracted malaria [2].
Sub-Sahara Africa is the most hit with malaria due repeated exposure with malaria infection. ITNs have a mean protective efficacy against malaria episodes of approximately $50 \%$ in highly endemic areas of Africa and have also been found to reduce overall mortality by $63 \%$ in villages using impregnated nets [3].

Insecticide treated nets (ITNs) are the most important malaria prevention, control and intervention strategy as they effectively reduce malaria morbidity and mortality in high endemic areas due the sequestration of malaria parasite in 
placenta leading to the impeded trans-placental nutrient transport[4]. Insecticide treated mosquito bed nets have been advocated for as the most preventive tools against malaria especially in sub-Saharan Africa for its overall reduction and transmission [5].

In Kenya malaria accounts for 30 percent of all outpatient cases and it causes high morbidity and mortality with negative effects on other sectors of the national economy [6] as well for the Jaggery and tea workers [7]. In 2012, one in every 20 deaths from malaria worldwide occurred in Kenya resulting into over 300,000 deaths [8]. Therefore, the extent to which nets are owned and 3 in every 4 Kenyans are at risk [9] of contracting malaria and these leaves us with a lot of question whether net are properly used. Malaria is [10] still a dreadful disease and cause high tolls annually.

Nearly half of patient seeking outpatient services in Kisii County suffer from malaria [11]. Health facilities in Kisii County continue to be recording high percentage of people with malaria. The Ministry of health is concerned as to whether mosquito nets provided [12] are put to proper use in areas mostly affected in South Mugirango Sub- County, Kisii, Kenya.

Therefore this study will seek to bridge this literature gap and provide information to spearhead the Jaggery and tea workers perceptions on ITNs use in the prevention of malaria in South Mugirango Kisii County, Kenya. Perceptions on the ITNs use in the prevention of malaria will influence interventions aimed at decreasing morbidity and mortality among the Jaggery and tea workers. The policy makers and program planners will utilize this study information to mobilize the appropriate needed resources.

\section{Setting and Target Population}

This was a community based cross sectional descriptive study. The quantitative and qualitative data was collected. The study area was in South Mugirango sub county Kisii, Kenya which yearly experiences high prevalence of highland malaria. The study population included both male and female Jaggery and tea workers aged 18-49 years at risk of contracting malaria infection.

The sample size was determined based on the prevalence of malaria which was $14.5 \%$ confirmed cases. The participants were systematically sampled from the list of KTDA and sugarcane out-grower workers. Desired sample size of 209 Jaggery and tea workers was obtained using predetermined interval. The selected subjects were interviewed on the use of ITNs in the prevention of malaria.

The inclusion criteria was those both male and female working in the sugarcane farms and tea estates for the last six months aged 18-49 years. The study excluded those who were mentally handicapped and not capable of verbally communicating and below 18 years of age. Quantitative data was collected through interviewer administered structured questions. Qualitative data was obtained from interview schedule and Focused Group Discussion and Key Informant. The questionnaire sought information on socio- demographic, perception and beliefs regarding ITNs use in the prevention of malaria.

Data collected was cleaned, coded and analyzed using SPSS version 20 with $95 \% \mathrm{CI}$ and statistical significance set at $\mathrm{p}<0.05$. Chi - Squire was used to establish relationship on ITNs use. Ethical considerations was sought from Kenyatta University Ethical Review Committee and permit issued by (NACOSTI)-National Commission for Science, Technology and Innovation. Informed consent was also sought from the study participants and high level of confidentiality maintained during the period with guaranteed autonomy. The respondents were allowed to withdraw at their own will if wished to do so.

\section{Results}

This shows the results of perception and beliefs on ITNs use among the Jaggery and tea workers.

\subsection{Demographic and Socio-Economic Characteristics of the Jaggery and Tea Workers}

A total of 209 Jaggery and tea workers consented to be interviewed and their data was included in the analysis (Table 1) details the demographic of the study population.

Table 1. Characteristics of the Jaggery and Tea Workers.

\begin{tabular}{lll}
\hline Variables & Frequency $\mathbf{~}$ & Percent \\
\hline Gender & & \\
Male & 116 & 56 \\
Female & 93 & 44 \\
Age & & \\
18-28 years & 69 & 33 \\
29-39 years & 85 & 41 \\
40-50 years & 55 & 26 \\
Marital status & & \\
Single & 42 & 20 \\
Married & 95 & 45 \\
Widowed & 23 & 11 \\
Divorced & 29 & 14 \\
Living together & 9 & 4 \\
No response & 11 & 5 \\
Education level & & \\
None & 14 & 7 \\
Primary & 29 & 14 \\
Secondary & 88 & 42 \\
College & 62 & 30 \\
Vocational training & 16 & 7 \\
Occupation & 87 & 42 \\
Jaggery worker & 116 & 56 \\
Tea worker & 6 & \\
Others & & \\
\hline & & \\
\hline
\end{tabular}

\subsubsection{Gender of the Jaggery and Tea Workers}

In this study (Table 1) Characteristics of the Jaggery and tea worker, it was found out that there were more males 116 $(56 \%)$ than females workers $93(44 \%)$ in the industry.

\subsubsection{Age of the Jaggery and Tea Workers}

The mean age of the respondents was 34years with $(\mathrm{SD})=6.2$ years and ranged between 18 and 50 years. Most of the Jaggery and tea workers (Table 1) were between the ages 29-39 years at 
$85(41 \%)$ while those aged between $18-28$ years were $69(33 \%)$ with 55 (26\%) aged between 40-50 years.

\subsubsection{Marital Status of the Jaggery and Tea Workers}

On marital status (Table 1) it was found out that 95(45\%) were married with $42(20 \%)$ being single or living alone, while29 (14\%) were divorced with 23 (11\%) being widowed and the rest $11(5 \%)$ having no response with a few $9(4 \%)$ living together without any formal arrangement.

\subsubsection{Level of Education of the Jaggery and Tea Workers}

On the level of education (Table 1 ) the study revealed that $88(42 \%)$ had secondary education with $62(30 \%)$ having had college education while29 (14\%) had primary education with $16(7 \%)$ having vocational while $14(7 \%)$ had no education at all. This means that those without education were found to be the lowest users of ITNs.

\subsubsection{Occupation of the Jaggery and Tea Workers}

This study revealed that more than half of the respondents (Table 1) 116 (56\%) were tea workers while 87 (42\%) were Jaggery workers with only $6(2 \%)$ percent being engaged with other small scale activities.
Most 74 of 116 (18\%) of the tea workers were found using the ITNs in carrying tea to the tea buying centers and the reasons was said that nets and netting material were portable and easy to carry compared with the baskets.

The study found out that $42(20 \%)$ of the Jaggery workers cited the reasons for non-use of ITNs was that they worked at night and used the ITNs in making Jaggery shades with the remains from sugarcane to protect them from adverse conditions like rain and hot sunshine during working hours.

\subsubsection{Level of Income of the Household}

Every household at least accessed some little income (Figure 1) below. This was from the proceeds of picking tea and Jaggery activities in the sugarcane industry. Household income was found to be contributing factor to ITNs use among the Jaggery and tea workers. About $12.4 \%$ earned less than Kshs 2500 while $13.4 \%$ earnedKshs 2600-5100. Only $30.6 \%$ of the household earned between Kshs 5200-7700, (62)29.7\% earned Kshs7800-10300, 19(9\%) earned Kshs10400-12900, with 10 (4.9\%) earned more than Kshs13000.

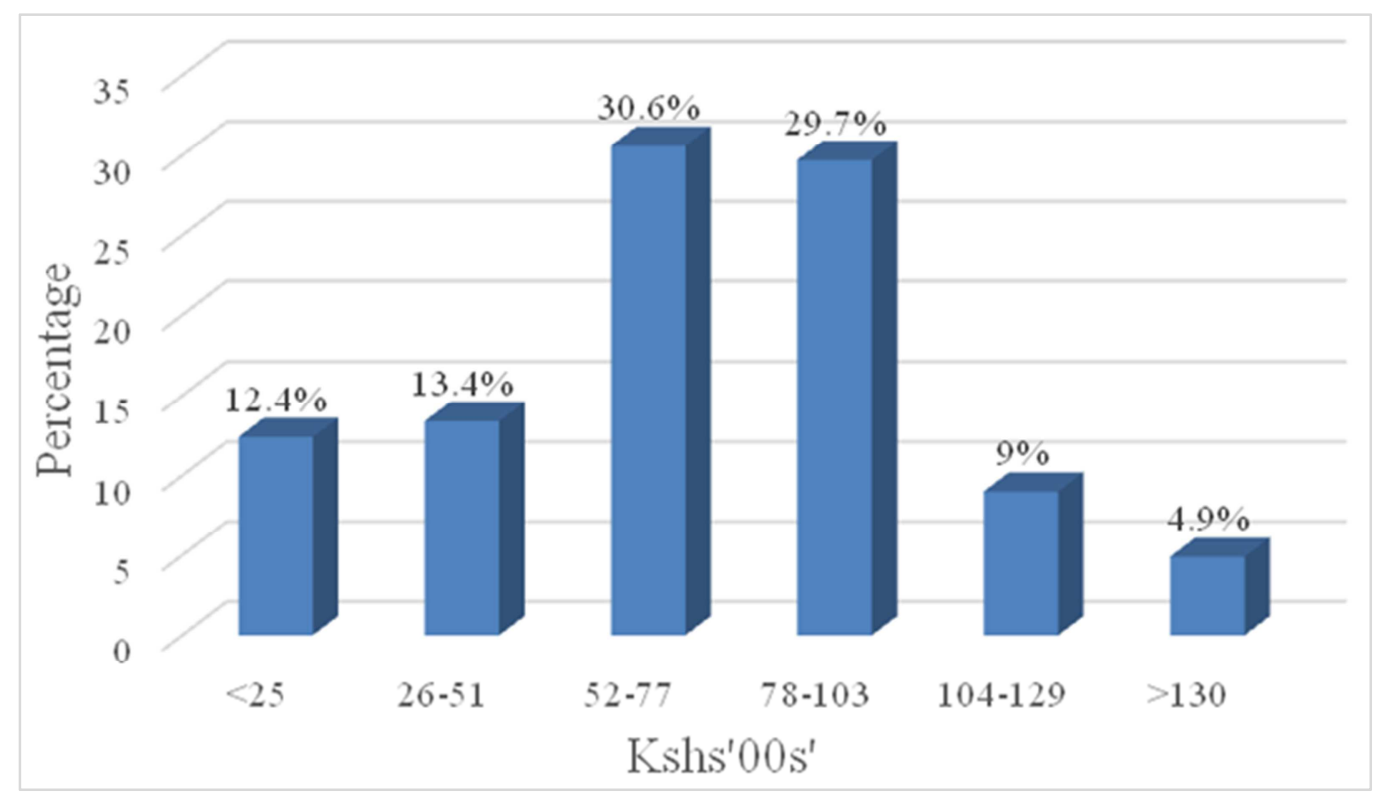

Figure 1. Household income levels of the Jaggery and Tea workers.

The average income per household was Kshs $77 \pm 26.50$. From FGDs it was revealed that workers in the Jaggery and tea industry earned very little to sustain them and perceived it not enough to purchase ITNs.

\subsection{Demographic Factors Versus ITNs Use}

From the above (Table 2) 99(51.6\%) of gender were male while $93(48.4 \%)$ were female. Therefore, gender was found to play a great role and was statistically significant $\mathrm{P}<0.001$ among the ITNs users. Among the non- users of ITNs $17(100 \%)$ were also found to be males and were not having any in their households.
Age and marital status were found not to be statistically significant. The majority of ITNs users' age ranged between 29-39 years with non- users age ranging from 18-29 years respectively. On marital status 95 (49.5\%) who were married and were found to be among the users of ITNs while 17 $(100 \%)$ of the singles were found to be non -users of ITNs in this study.

Education and occupation were also found to be statistically significant with the $\mathrm{P}<0.001$ and $\mathrm{P}<0.003$ respectively. Most 88 $(45.5 \%)$ of the Jaggery and tea workers had attained secondary education. On their occupation it was revealed that 105 (54.5\%) were tea workers and users of ITNs. 
Table 2. Demographic factors and ITN use.

\begin{tabular}{|c|c|c|c|}
\hline \multirow{2}{*}{ Variables } & \multicolumn{2}{|l|}{ ITN Use } & \multirow{2}{*}{ P-Value } \\
\hline & Yes n(\%) & No $n(\%)$ & \\
\hline Gender & & & $<0.001$ \\
\hline Male & $99(51.6 \%)$ & $17(100 \%)$ & \\
\hline Female & $93(48.4 \%)$ & $0(0.0 \%)$ & \\
\hline Age & & & 0.131 \\
\hline $18-28$ & $52(27.1 \%)$ & $17(100 \%)$ & \\
\hline $29-39$ & $85(44.3 \%)$ & $0(0.0 \%)$ & \\
\hline $40-50$ & $55(28.6 \%)$ & $0(0.0 \%)$ & \\
\hline Marital status & & & 0.362 \\
\hline Single & $25(13 \%)$ & $17(100 \%)$ & \\
\hline Married & $95(49.5 \%)$ & $0(0.0 \%)$ & \\
\hline Widowed & $23(12.0 \%)$ & $0(0.0 \%)$ & \\
\hline Divorced & $29(15.9 \%)$ & $0(0.0 \%)$ & \\
\hline Living together & $9(4.7 \%)$ & $0(0.0 \%)$ & \\
\hline No response & $11(5.7 \%)$ & $0(0.0 \%)$ & \\
\hline \multicolumn{4}{|l|}{ Education } \\
\hline None & $0(0.0 \%)$ & $14(82.4 \%)$ & $<0.001$ \\
\hline Primary & $26(13.5 \%)$ & $3(17.6 \%)$ & \\
\hline Secondary & $88(45.5 \%)$ & $0(0.0 \%)$ & \\
\hline College & $62(32.3 \%)$ & $0(0.0 \%)$ & \\
\hline Vocational training & $16(8.3 \%)$ & $0(0.0 \%)$ & \\
\hline Occupation & & & 0.003 \\
\hline Jagger worker & $87(45.3 \%)$ & $0(0.0 \%)$ & \\
\hline Tea worker & $105(54.7 \%)$ & $11(64.7 \%)$ & \\
\hline Others & $0(0.0 \%)$ & $6(35.3 \%)$ & \\
\hline
\end{tabular}

\subsection{Perception of ITNs Use Among the Jaggery and Tea Workers on Malaria Prevention}

ITNs are perceived to be a mosquito control intervention in preventing malaria morbidity and mortality among the Jaggery and tea workers in high endemic areas. Most of the Jaggery and tea workers109 $(52 \%)$ perceived malaria to be caused by mosquitoes while $25(12 \%)$ perceived that it is caused by rain. Also 16(8\%) perceived it that eating sugarcane caused malaria with $27(13 \%)$ had perceived dirty environment to have been the cause. This study further established that 66(31.5\%) perceived it to cause suffocation while $43(20.5 \%)$ also perceived to cause irritation with 53 (25.3\%) perceiving it to cause dreams (Table 4) below.

\subsection{Perceived Effectiveness of ITNS Use on Malaria Prevention}

On the perceived effectiveness about ITNs use among the Jaggery and tea workers a five range scale was used. The scale ranged from not effective to very effective to establish their feelings on ITNs. 78 (37.8\%) said nets were average in malaria prevention $45(21.9 \%)$ said less effective while 43 $(20.9 \%)$ and $25(11.9 \%)$ said that they were very effective and only $16(7.5 \%)$ said not effectively as seen in the (Figure 2) below.

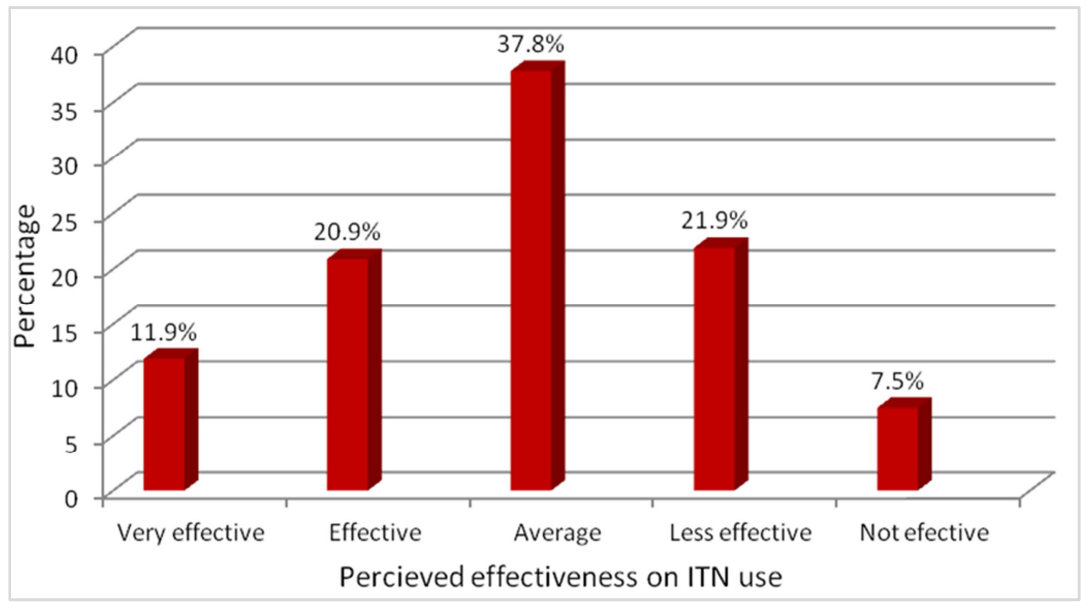

Figure 2. Perceived Effectiveness on ITNs use.

The Perceived risk of malaria and benefits of the nets by the population also drive demand [13] in a Nigerian study found that households with a recent attack of malaria and those with higher willingness to pay were more likely to purchase a net than their counterparts. Such communities have a perceived need for utilizing ITNs.

\subsection{Perceived Benefits and Barriers Related to Use of Itns Among the Jaggery and Tea Workers}

On this question there were multiple responses as the majority $153(73.1 \%)$ said that ITNs were necessary in preventing malaria among the Jaggery and tea workers. However, the minority $56(26.9 \%)$ of respondents perceived ITNs as not necessary (Table 3 ) below.
Table 3. Perceived Benefits of ITNs use.

\begin{tabular}{lll}
\hline Perceived benefits of ITNs & Frequency & Percent \\
\hline Necessary & 153 & 73.1 \\
Not necessary & 56 & 26.9 \\
Total & 209 & 100 \\
\hline
\end{tabular}

It was noted from this study that as much the respondents said it was necessary; utilization was still low as many suffered several malaria episodes. This was due to the fact that some still believed that they cause irritation and dreams (Table 4) below. Participants and key informants knew that mosquito nets were a useful preventive measure against malaria and that pregnant Jaggery and tea workers and children were supposed to sleep under nets since they are the 
most vulnerable groups. However, the availability and use of the nets in this area was found to be very low. "For us here we do not use mosquito nets...I also do not have one" (28year-old pregnant Jaggery worker commented).

\subsection{Perception on ITNs Use, Beliefs and Mode of Malaria Transmission}

Table 4. Perception of ITN use, Beliefs and Mode of Malaria Transmission.

\begin{tabular}{|c|c|c|c|}
\hline Perception of ITNs use, beliefs and mode of malaria transmission & Response & Frequency N & Percentages \\
\hline \multirow{5}{*}{ Cause of malaria (unprompted) } & Mosquito & 109 & 52 \\
\hline & Dirty environment & 27 & 13 \\
\hline & Stagnant water & 32 & 15 \\
\hline & Eating sugarcane & 16 & 8 \\
\hline & Rained on & 25 & 12 \\
\hline \multirow{4}{*}{ What are ways of preventing malaria? } & Through net & 116 & 55.5 \\
\hline & Malaria drugs & 46 & 22 \\
\hline & Use of ITNs & 17 & 8.2 \\
\hline & I don't know & 10 & 4.8 \\
\hline \multirow{6}{*}{ Reasons for not sleeping under net } & Cause suffocation & 66 & 31.5 \\
\hline & Cause irritation & 43 & 20.5 \\
\hline & Cause dreams & 53 & 25.3 \\
\hline & No mosquito & 21 & 10.3 \\
\hline & I don't have & 18 & 8.6 \\
\hline & I forgot & 8 & 3.6 \\
\hline
\end{tabular}

On perception of ITNs use, beliefs and mode on cause of malaria transmission $109(52 \%)$ said mosquito, 32(15\%) said stagnant water while $27(13 \%)$ said dirty environment. Only a few $16(8 \%)$ and $25(12 \%)$ said eating sugarcane and rain respectively.

Also the respondents were asked on ways of preventing malaria to establish their perception116 (55.5\%) said through nets $46(22 \%)$ said through anti malaria drugs while 20 $(9.5 \%)$ said clean environment with a few $17(8.2 \%)$ said through use of ITNs and only $10(4.8 \%)$ said they didn't know (Table 4) above.
The respondents were then asked the reasons of not sleeping under net to establish their perception 66 (31.5) percent said that it causes irritation, $53(25.3 \%)$ said it causes dreams, $43(20.5 \%)$ said suffocation, and a few $21(10.3 \%)$ said there were no mosquito while $18(8.6 \%)$ did not have net and the rest $8(3.6 \%)$ said they forgot. On Perceived cause of malaria in particular, $52 \%$ said mosquito. This findings is in contrast with a study [14] in Western Kenya which showed that though people know what causes malaria, they still do not use ITNs (Table 4) above.

\subsection{Perceived Dangers of Malaria Among the Jaggery and Tea Workers}

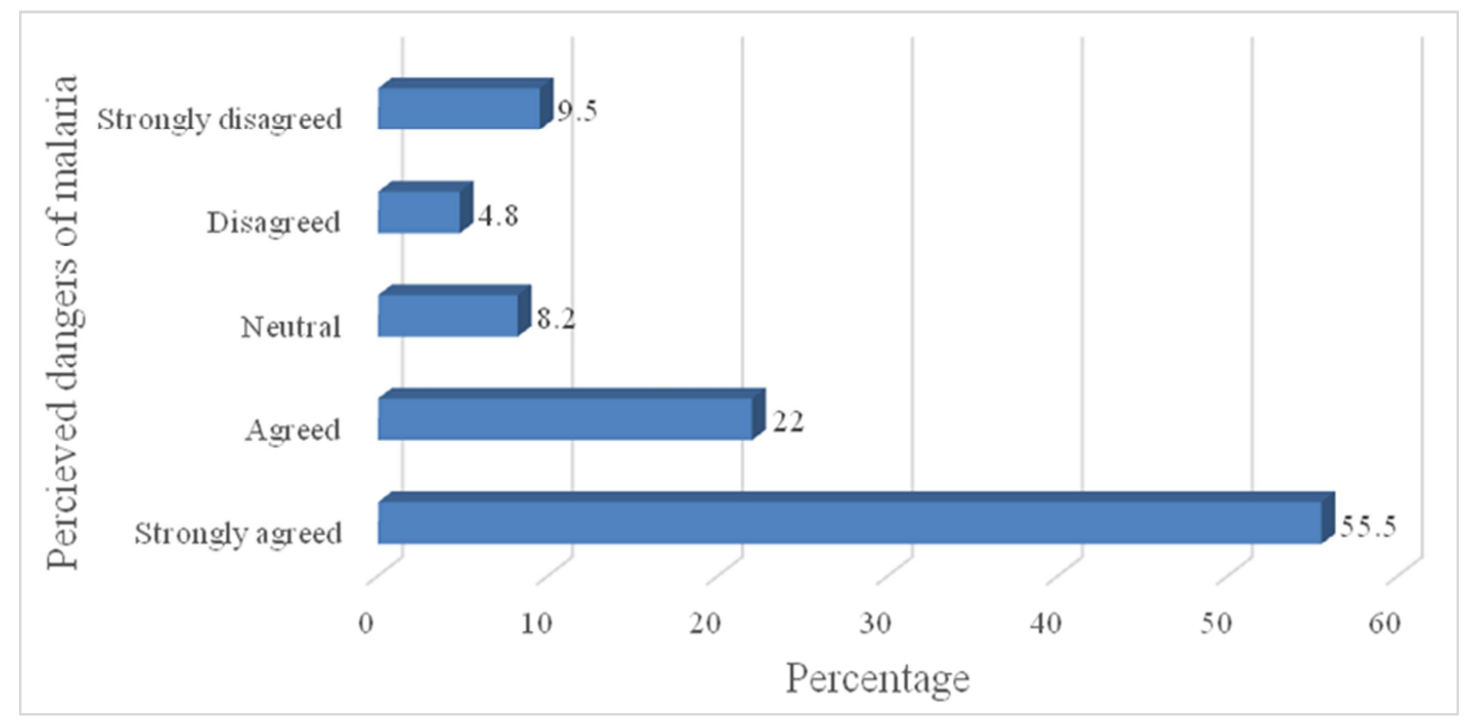

Figure 3. Perceived dangers of Malaria among the Jaggery and tea workers.

The respondents (Figure 3) above were asked to what extent they agreed or disagreed that malaria is a dangerous disease. The majority $116(55.5 \%)$ strongly agreed that malaria is dangerous while $46(22 \%)$ agreed that it cause death. A few $17(8.2 \%)$ were neutral while $10(4.8 \%)$ disagreed. Those who strongly disagreed $20(9.5 \%)$ said that 
rainy conditions were causes of malaria and these led to number of days lost. This study revealed that those who were neutral were found not having any ITNs.

\section{Discussion}

This study targeted 209 Jaggery and tea workers because this group contributes a lot to the agricultural sector which is the backbone of the country's economy. The study was therefore set to establish the Jaggery and tea workers perceptions on ITNs use in the prevention of malaria in South Mugirango Sub County, Kisii, Kenya.

From the above (Table 2) among the ITNs users, $99(51.6 \%)$ of gender were male and $93(48.4 \%)$ were female respectively. Therefore, gender was found to play a great role and was statistically significant $\mathrm{P}<0.001$ among the ITNs users. Among the non- users of ITNs $17(100 \%)$ were also found to be males and were not having any in their households.

Age and marital status were found not to be statistically significant. The majority of ITNs users' age ranged between 29-39 years with non- users age ranging from 18-29 years respectively. On marital status $95(49.5 \%)$ who were married and were found to be among the users of ITNs while 17 $(100 \%)$ of the singles were found to be non -users of ITNs in this study.

Education and occupation were also found to be statistically significant with the $\mathrm{P}<0.001$ and $\mathrm{P}<0.003$ respectively. Most 88 (45.5\%) of the Jaggery and tea workers had attained secondary education. This study revealed that all those who had attained past secondary education were found to be users of ITNs among the group understudy. Therefore education act as a transformative agent to the improvement of their perceptions on ITNs use in the prevention of malaria. On their occupation it was revealed that 105 (54.5\%) were tea workers and users of ITNs.

On the perceived feelings about ITNs use a five range scale was used. The scale ranged from not effective to very effective. Seventy of the respondents $(37.8 \%)$ said nets were average in malaria prevention $45(21.9 \%)$ said less effective while $43(20.9 \%)$ and $25(11.9 \%)$ said very effective and only $16(7.5 \%)$ said not effectively as seen in the (Figure 2) above. The findings were similar with the one done by $[15,16]$ on the reasons for not using net. This study found out that those $7.5 \%$ who said that it was not effective had visited health center for malaria treatment more than three times in the last six months. Therefore, this study concurred with the one done [13] in a Nigerian study who also found that households with a recent attack of malaria more likely to purchase a net than their counterparts. Furthermore, a study by [17] comparing the cost of diagnosis and treatment of malaria with ITNs distribution showed the cost of ITNs distribution was cheaper than diagnosis.

Findings on the perceived benefit on ITNs use among the Jaggery and tea workers, the majority $73.1 \%$ percent said that ITNs were necessary in preventing malaria among the Jaggery and tea workers. This study also concurred with [18] on perceived need of bed net after reduced malaria episodes. However, the minority $26.9 \%$ percent of respondents perceived ITNs as not necessary and in the construct model by [19] shows perceptions to have high correlation with health related behavior. It was noted from this study that as much the respondents said it was necessary; utilization was still low due to low level of acceptance and recognition. This study concurs with one done by [20] who also found that even if ITNs are purchased and used must be recognized and accepted because the chemical terms insecticides and its toxicity attached influence its use. This was due to the fact that even though some slept under net still they suffered from malaria episodes due to their behavior on use as this concurs with study by [21] behavioral model and this let to frequenting the hospital more than three times in the last six months. This study also concurred with [22] who found that malaria is dangerous attributed with sequestration leading to impeded trans- placental nutrient transport. On perceived risks of malaria [23] also found that people often seek health services due to fears posed by mosquito parasite.

Respondents perception on ITNs use and mode of malaria transmission the majority109 (52\%) said that it is caused by mosquito, 32(15\%) said stagnant water while $27(13 \%)$ said dirty environment. Only a few $16(8 \%)$ and $25(12 \%)$ said eating sugarcane and rain respectively. From this information it was revealed on what they believed to cause malaria. Also the respondents were asked on ways of preventing malaria to establish their perception. 116 (55.5\%) said through nets 46 (22\%) said through anti malaria drugs while $20(9.5 \%)$ said clean environment with a few 17(8.2\%) said through use of ITNs and only $10(4.8 \%)$ said they didn't know. This study concurred with one done by [24, 25] on malaria prevention who found that knowledge attitudes and practices influence ITNs use in western Nigeria and to whether nets are put to proper use respectively.

The respondents were then asked the reasons of not sleeping under net to establish their perception $66(31.5 \%)$ said that it causes irritation, $53(25.3 \%)$ said it causes dreams, $43(20.5 \%)$ said suffocation and a few $21(10.3 \%)$ said there were no mosquito while $17(8.1 \%)$ did not have net and the rest $18(8.6 \%)$ said they forgot. This showed that although they were aware on what causes malaria they ignorantly never used the nets due to variations attributed by socioeconomic status and seasons [26]. Study on bed nets use and acceptance by $[27,28]$ had also found it to be true that perception always hinders use.

When asked whether the respondents agreed or disagreed with the fact that malaria is a dangerous disease among the Jaggery and tea workers, the majority strongly agreed 116 $(55.5 \%)$ that is malaria dangerous and these concurred with study by [29] on the economic costs of malaria at household. They gave reasons to support their perception such as it disturbs daily activities, while $46(22 \%)$ agreed that it causes death. A few $17(8.2 \%)$ were neutral while $10(4.8 \%)$ disagreed. Those who strongly disagreed $20(9.5 \%)$ said that rainy conditions were cause of malaria and these led to number of days lost. Therefore when people perceive malaria to be dangerous then need factor 
comes hand as they will try to find the solution for their problems. Those who were neutral were also found not having any net in their households. This study concurs with [30] in Uganda who found that many people perceived malaria to be caused by rain, cold weather or drinking cold water and not by mosquitoes.

\section{Conclusion}

This study concludes that the respondents perceived malaria to be caused by dirty environment, being rained on and eating sugarcane. Therefore low level on the use of ITNs among the Jaggery and tea workers were attributed by their perception and cultural factors as well as poor and inconvenient accommodation to hang the net. The study also found the Jaggery and tea workers perceived the ITNs to cause suffocation, irritation and dreams. Effectiveness largely depended on the knowledge and perceptions of the people in the household who directly use them.

In regard to perceptions and beliefs, the findings of this study showed that perceptions about ITNs influenced the use of ITNs among the Jaggery and tea workers within their household. In case they received visitors the head of the household decided who was to use the ITNs. The negative perceptions and beliefs among the Jaggery and tea workers led to low usage of ITNs as this led to more hospital visitation due to malaria episodes.

\subsection{Recommendation}

A study is required on how to improve the negative perception on the ITNs use among the Jaggery and tea workers in the prevention of malaria. In highly prevalent areas it is known that people get used to malaria sickness and with time, they adopt to the disease. Therefore there is a possibility that malaria is attributed to other causes like being rained on, dirty environment and chewing sugarcane. There is need for more research to investigate why people who perceive a malaria disease as dangerous that cause ill health among the Jaggery and tea workers do not take adequate preventive measures with the ITNs and instead they perceive them to cause dreams, suffocation and irritation.

\subsection{Recommendations for Further Study}

a. There is need to develop a health promotion package based on perceived factors that demystified the negative perceptions that led to low use of ITNs among the Jaggery and tea workers.

\section{Acknowledgements}

We sincerely thank all the Jaggery and tea workers who voluntary participated in this study and the Health Director in the County Government of Kisii for allowing this research to be conducted and permission to publish this findings. Lastly we are grateful to all those people who helped us one way or the other to make this study a success.

\section{References}

[1] WHO: World Malaria Report 2013. 2013, Geneva: World Health Organization Google Scholar.

[2] WHO, (2013): Malaria vector control and personal protection: report of a WHO study group, Geneva, (2006).

[3] Lengeler C Snow RW. From efficacy to effectiveness: Insecticide treated bed nets in Africa. Bulletin of World Health Organization 2000.74: 325-32.

[4] McCorwick M. 2005]. Costing the distribution of insecticide-treated nets: a review of cost and costeffectiveness studies to provide guidance on standardization of costing methodology.

[5] WHO, 2010. World Malaria Report 2010. 2010, Geneva: World Health Organization Google Scholar.

[6] Adedotun A. A., Salawu O. T., Morenikeji, O. A and Odaibo A. B: Plasmodial infection and heamatological parameters in febrile patients in a hospital in Oyoo town South Western Nigeria 2012.

[7] Chuma JM, Thiede M, Molyneux CS: Rethinking the economic costs of malaria at the household level: evidence from applying a new analytical framework in rural Kenya. Malaria J (2006), 5:76. .

[8] AL Adhroey, Nor ZM, AL Mekhlafi HM, Mahud R Malar J 2010 MAY 24,9,137 doi:-1186/1475-2875-9-137. Effects of malaria in communities.

[9] WHO, $2011 \mathrm{WHO}$, (2011): Malaria vector control and personal protection: report of WHO study group, Geneva, (2011).

[10] White NJ, Dondorp AM, Faiz A, Mishra S and Hien TT 2012. New global estimates of malaria deaths. Lancet 380, 559-560.

[11] Republic of Kenya Ministry of Health (MOH 2012). Households Surveys in Kenya.

[12] Ministry of Health Kisii County (MOH 2017): On whether the nets issued are put to proper use or not.

[13] Onwujekwe O, Hanson K, Fox-Rushby J: Inequalities in purchase of mosquito nets and willingness to pay for insecticide-treated nets in Nigeria: challenges for malaria control interventions. Malar J. 2004, 3: 6http://www.malariajournal.com/content/3/1/6.PubMedCentral View ArticlePubMedGoogle Scholar.

[14] Alaii J, Hawley W, Kolczak M, ter Kuile F, Gimnig J, Vulule J, Odhacha A, Oloo A, Nahlen B, Phillips-Howard P: Factors affecting use of permethrin-treated bed nets during a randomized controlled trial in western Kenya. Am J Trop Med Hyg. 2003, 68: 137-141. PubMedGoogle Sc.

[15] Pulford J, Hetzel MW, Bryant M, Siba PM, Mueller I: Reported reasons for not using a mosquito net when one is available: a review of the published literature. Malar J. 2011, 10: 83-10.1186/1475-2875-10-83. PubMed Central View Article Pub Med Google Scholar.

[16] Pulford J, Oakiva T, Angwin A, Bryant M, Mueller I, Hetzel M: Indifferent to disease: a qualitative investigation of the reasons why some Papua New Guineans who own mosquito nets choose not to use them. Soc Sci Med. 2012, 75: 22832290. 10.1016/j.socscimed.2012.08.030.View Article Pub Med Google Scholar. 
[17] Michael T W, Lesong C, Richard C and Azra C Ghani: cost and cost-effectiveness of malaria control interventionsansystematic review; malaria journal 2011 10:337.

[18] Beer N, Ali AS, Eskilsson H, Jansson A, Abdul-Kadir FM, Rotllant-Estelrich G, Abass AK, Wabwire-Mangen F, Björkman A, Källander K: A qualitative study on caretakers' perceived need of bed-nets after reduced malaria transmission in Zanzibar, Tanzania. BMC Public Health. 2012, 12: 60610.1186/1471-2458-12-606. PubMed Central View Article Pub Med Google Scholar.

[19] Nuwaha F. Peoples perceptions of malaria in Mbarara Uganda. Trpical medicine and International Health 2002.7.462-70.

[20] Winch, PJ, Makemba AM, Kamazima, SR. Social cultural factors affecting rates of regular re-treatment of mosquito nets with insecticides in Bagamoyo district in Tanzania. Tropical medicine and International Health 2007.2:760-70.

[21] Andersen R. A. (1968), Behavioral Model of Families' Use of Health Services. Chicago, IL: Center for Health Administration Studies, University of Chicago.

[22] Michael. T White, Lesong Conteh, Richard Cibulkis and Azra C Ghani 2011. Costing the distribution of insecticide-treated nets: a review of cost and cost-effectiveness studies to provide guidance on standardization of costing https://doi.org/10.1186/1475-1475-10-337.

[23] Bauch JA, Gu JJ, Msellem M, Mårtensson A, Ali AS, Gosling $\mathrm{R}$, Baltzell KA: Perception of malaria risk in a setting of reduced malaria transmission: a qualitative study in Zanzibar. Malar J. 2013, 12: 75-10.1186/1475-2875-12-75. PubMed Central View Article Pub Med Google Scholar.
[24] Erhun et al (2005) Malaria Prevention: Knowledge, attitude and practice in south western Nigeria community, African journal of biomedical research 8(2005):25-29ISSN 11195096.

[25] Baume C, Marin M: Intra-household mosquito net use in Ethiopia, Ghana, Mali, Nigeria, Senegal and Zambia: Are nets being used? Who in the household uses them? Am J Trop Med Hyg (2007), 77:963-971.

[26] Somi MF, Butler JR, Vahid F, Njau J, Kachur SP, Abdulla S: Is there evidence for dual causation between malaria and socioeconomic status? Findings from rural Tanzania. Am J Trop Med Hyg (2007), 77:1020-1027.

[27] Heggenhougen HK, Hackenthal. V, Vivek P. Bed net use and its acceptance at the local level Chapter 6 in the behavior and societal aspect of malaria programs: an introduction and annonated biography; Geneva special, programmes for research and training in Tropical Diseases (TDR), STR/SEB/VOL/03.1.

[28] Koenker HM, Loll D, Rweyemamu D, Ali AS: A good night's sleep and the habit of net use: perceptions of risk and reasons for bed net use in Bukoba and Zanzibar. Malar J. 2013, 12: 203-10.1186/1475-2875-12-203. PubMed Central View Article Pub Med Google Scholar.

[29] Chuma JM, Thiede M, Molyneux CS: Rethinking the economic costs of malaria at the household level: evidence from applying a new analytical framework in rural Kenya. Malaria J (2006), 5:76. Pub Med.

[30] Nuwaha F. Peoples perceptions of malaria in Mbarara Uganda. Trpical medicine and International Health 2002.7.462-70. 